\title{
Trends and cycles in macro series: The case of US real GDP
}

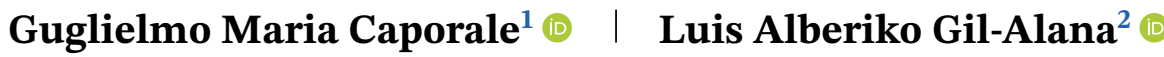

\author{
${ }^{1}$ Department of Economics and Finance, \\ Brunel University London, London, UK \\ ${ }^{2}$ Faculty of Economics and ICS, \\ University of Navarra, Pamplona, Spain

\section{Correspondence} \\ Guglielmo Maria Caporale, Department of \\ Economics and Finance, Brunel Univer- \\ sity London UB8 3PH, UK. \\ Email:Guglielmo- \\ Maria.Caporale@brunel.ac.uk

\section{Funding information} \\ Ministerio de Economía, Industriay \\ Competitividad, Gobierno de España, \\ Grant/Award Number: ECO2017-85503-R
}

\begin{abstract}
This paper proposes a new modeling framework capturing both the long-run and the cyclical components of a time series. As an illustration, we apply it to four US macro series, namely, annual and quarterly real gross domestic product (GDP) and GDP per capita. The results indicate that the behavior of US GDP can be captured accurately by a model incorporating both stochastic trends and stochastic cycles that allows for some degree of persistence in the data. Both appear to be mean reverting, although the stochastic trend is nonstationary, while the cyclical component is stationary, with cycles repeating themselves every 6-10 years.
\end{abstract}

\section{KEYWORDS}

cycles, fractional integration, GDP, GDP per capita, long memory, trends

\section{JEL CLASSIFICATION \\ C22, E32}

\section{1 | INTRODUCTION}

This paper proposes a new modeling framework capturing both the long-run and the cyclical components of a time series. It is specified such that its spectral density function contains two poles or singularities, one corresponding to the long run or zero frequency (i.e., to the long-run equilibrium level of the series), the other to a nonzero frequency (which is related to a cyclical pattern repeated approximately every $6-10$ years). The proposed model is very general: it extends the 
classical framework based on unit roots by allowing for fractional integration, and considers both deterministic and stochastic patterns, at the zero and cyclical frequencies, including both longand short-memory components. The cyclical patterns are modeled using Gegenbauer processes.

The suggested methodology is then applied to analyze the behavior of four US macro series, namely, annual and quarterly gross domestic product (GDP) and GDP per capita. The results indicate that the behavior of US GDP can be captured accurately by a model incorporating both stochastic trends and stochastic cycles that allows for some degree of persistence in the dynamics of the series. Both appear to be mean reverting, although it is found that the stochastic trend is nonstationary while the cyclical component is stationary, with cycles repeating themselves every 6-10 years. Deterministic (linear and nonlinear) terms were also incorporated into the model but were not found to be statistically significant in any case.

The layout of the paper is as follows. The next section briefly reviews the main approaches to modeling GDP found in the literature. The following one presents the statistical model. The two final ones discuss data and the empirical results and offer some concluding remarks.

\section{2 | LITERATURE REVIEW}

GDP, whether nominal, real, or per capita, is typically a nonstationary variable in most developed countries. For many years, the standard modeling approach was to use deterministic functions of time, usually of a linear form, as in the following specification:

$$
y_{t}=\alpha+\beta t+x_{t}, t=1,2, \ldots,
$$

where $\left\{y_{t}, t=1,2, \ldots, T\right\}$ is the observed (GDP) series, $\alpha$ and $\beta$ are the coefficients on an intercept and a linear time trend, respectively, and $x_{t}$ is assumed to be covariance stationary, usually of the autoregresssive moving average (ARMA) form, to capture short-run and cyclical patterns in the data. Therefore, the process followed by $x_{t}$ can be represented as

$$
\varphi(L) x_{t}=\theta(L) \varepsilon_{t}, t=1,2, \ldots,
$$

where $\varphi(L)$ and $\theta(L)$ stand for the autoregressive (AR) and moving average components of the series, respectively. This modeling framework was dominant in the literature until the publication of a very influential paper by Nelson and Plosser (1982), who examined 14 US macroeconomic series, and by applying the tests developed by Fuller (1976) and Dickey and Fuller (1979) found evidence of unit roots, coming to the conclusions that the behavior of these variables except one could be better described in terms of stochastic trends, that is, as in the following model including an intercept:

$$
y_{t}=\alpha+y_{t-1}+x_{t}, t=1,2, \ldots,
$$

where $x_{t}$ is $I(0)$ and can be represented as in (2). ${ }^{1}$ This model has been widely employed in the macro literature, and in the last 20 years, many additional unit root/stationary tests have been

\footnotetext{
${ }^{1}$ For our purposes, we define an $I(0)$ process as a covariance stationary process, for which the infinite sum of the autocovariances is finite. Alternatively, in the frequency domain, it can be defined as a process with a spectral density function that is positive and finite at all frequencies in the spectrum.
} 
developed (Elliot et al., 1996; Kwiatkowski et al., 1992; Ng \& Perron, 2001; Phillips \& Perron, 1988; etc.). These two specifications, i.e., the deterministic trend model as in (1) and the stochastic trend model as in (3), can coexist within the same framework if $x_{t}$ in (1) contains a unit root, the main difference between the two models being the treatment of shocks, which have transitory effects in the case of (1) but permanent ones in the case of (3). However, a process may display nonstationary, persistent behavior but still be mean reverting as in the $I(d)$ models with a differencing parameter $d$ lying in the interval $[0.5,1)$. In general, in such models, $x_{t}$ is specified as

$$
(1-L)^{d} x_{t}=u_{t}, t=1,2, \ldots,
$$

where $L$ stands for the lag operator (i.e., $L x_{t}=x_{t-1}$ ); $d$ can be any real value and $u_{t}$ is $I(0)$ (defined as in footnote 1). Variants of this model have been used to analyze the behavior of GDP in various countries (see, e.g., Caporale \& Skare, 2014; Dalkir, 2010; Ergemen, 2019; Mayoral, 2006; Michelacci \& Zaffaroni, 2000; Stengos et al., 2018).

Equation (4) is clearly more general than the classical stationary $I(0)$ / nonstationary $I(1)$ framework because it allows for a more cases, including (i) anti-persistence $(d<0)$; (ii) shortmemory or $I(0)$ processes $(d=0)$; (iii) long-memory stationary processes $(0<d<0.5)$; nonstationary mean-reverting processes $(0.5 \leq d<1)$; (iv) unit roots $(d=1)$; and explosive patterns $(d>1)$.

Cyclicality is another important feature of GDP series. There exists a large literature using different methods, such as time-varying transition probabilities Markov-switching regime models (see, e.g., Simpson et al., 2001), band pass filters (Christiano \& Fitzgerald, 1999), etc. A similar approach to equation (4) can also be used to allow stochastic cyclical processes to be fractional as in the following model:

$$
\left(1-2 \cos w L+L^{2}\right)^{d} x_{t}=u_{t}, \quad t=1,2, \ldots,
$$

with $\mu=\cos w$, and

$$
\left(1-2 \mu L+L^{2}\right)^{-d}=\sum_{j=0}^{\infty} C_{j, d}(\mu) L^{j},
$$

where $C_{j, d}(\mu)$ are orthogonal Gegenbauer polynomial coefficients defined recursively as

$$
\begin{gathered}
C_{0, d}(\mu)=1, \quad C_{1, d}(\mu)=2 \mu d, \\
C_{j, d}(\mu)=2 \mu\left(\frac{d-1}{j}+1\right) C_{j-1, d}(\mu)-\left(2 \frac{d-1}{j}+1\right) C_{j-2, d}(\mu), \quad j=2,3, \ldots .
\end{gathered}
$$

Gray et al. (1989, 1994) showed that $x_{t}$ in (5) is (covariance) stationary if $d<0.5$ for $\left|\mu=\cos w_{r}\right|<1$ and if $d<0.25$ for $|\mu|=1$. This process implies the existence of a pole or singularity at a nonzero frequency which corresponds to the cyclical pattern. Special cases of this model were analyzed by Athola and Tiao (1987a,b) and Bierens (2001) setting $d=1$, 
and by Phillip et al. (2018), Dissanayake et al. (2020) and others allowing $d$ to take fractional values. $^{2}$

In this paper, we combine the two models given by equations (4) and (5) in a single framework that is presented in the following section. Our novel approach encompasses the two cases of unit roots and fractional integration on the one hand and cyclicality on the other as special cases when the specific orders of integration are equal to zero.

\section{3 | A STATISTICAL MODEL FOR TRENDS AND CYCLES}

We propose a very general specification that incorporates both deterministic and stochastic trends, not only at the zero frequency but also at the nonzero (cyclical) frequencies, allowing for both long- and short-memory components. The model is the given by (6) below:

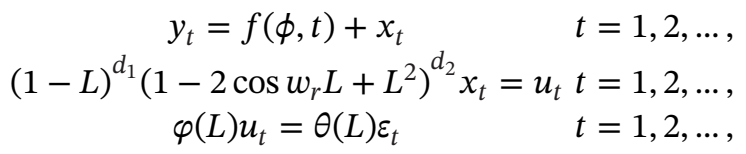

where $f$ is a function that can also be nonlinear, depending on time and the unknown parameter vector $\varphi ; L$ is the lag operator; $d_{1}$ and $d_{2}$ are the integration orders of the long-run and the cyclical frequencies, respectively, where $w_{r}=2 \pi \mathrm{r} / T$ with $r=T / j, j$ indicates the number of periods per cycle and $r$ the frequency with a singularity or pole in the spectrum; $u_{t}$ is $I(0)$ and displays weak dependence (as in equation (2) but replacing $x_{t}$ with $u_{t}$ ), and $\varepsilon_{t}$ is i.i.d. $N\left(0, \sigma^{2}\right)$. Therefore, the vector of parameters to be estimated is $\psi=\left[\varphi^{T}, d_{1}, d_{2}, r, \varphi_{1}, \ldots, \varphi_{p}, \theta_{1}, \ldots \theta_{\mathrm{p}}\right]^{T}$.

Robinson (1994) had previously proposed a general testing framework that includes as a special case a very similar specification to ours. He considered the model in (7) with a linear deterministic component:

$$
\begin{array}{cl}
y_{t}=\beta^{T} z_{t}+x_{t} & t=1,2, \ldots, \\
(1-L)^{d_{1}} \prod_{j=2}^{s}\left(1-2 \cos w_{r}^{j} L+L^{2}\right)^{d_{j}} x_{t}=u_{t} t & =1,2, \ldots, \\
\varphi(L) u_{t}=\theta(L) \varepsilon_{t} & t=1,2, \ldots,
\end{array}
$$

where $z_{t}$ is a $(k \times 1)$ vector of deterministic terms and/or weakly exogenous variables and $s$ represents the number of cyclical and/or seasonal patterns observed in the data. Within this set-up, he tested the nullhypothesis in (8):

$$
H_{o}: d=d_{o}
$$

where $d=\left[d_{1}, d_{2}, \ldots, d_{s}\right]^{T}$ and $d_{o}=\left[d_{10}, d_{20}, \ldots, d_{s o}\right]^{T}$ is an $(\mathrm{s} \times 1)$ vector of given real numbers.

Assuming now that $s=2$, the second equation in (7) becomes the same as the second one in (6), with the two coefficients $d_{1}$ and $d_{2}$ referring, respectively, to the long-run and cyclical components

\footnotetext{
${ }^{2}$ See Chung (1996) and Wu and Peiris (2018) for modeling with Gegenbauer processes.
} 
of the series. In this context, an LM test of (8) in (6) can be defined as in equation (9)

$$
\hat{R}=\frac{T}{\hat{\sigma}^{4}} \hat{a} \prime \hat{A}^{-1} \hat{a}
$$

where $T$ is the sample size, and

$$
\begin{gathered}
\hat{a}=\frac{-2 \pi}{T} \sum_{j}^{*} \psi\left(\lambda_{j}\right) g_{u}\left(\lambda_{j} ; \hat{\tau}\right)^{-1} I\left(\lambda_{j}\right) ; \quad \hat{\sigma}^{2}=\sigma^{2}(\hat{\tau})=\frac{2 \pi}{T} \sum_{j=1}^{T-1} g_{u}\left(\lambda_{j} ; \hat{\tau}\right)^{-1} I\left(\lambda_{j}\right) \\
\hat{A}=\frac{2}{T}\left(\sum_{j}^{*} \psi\left(\lambda_{j}\right) \psi\left(\lambda_{j}\right)^{\prime}-\sum_{j}^{*} \psi\left(\lambda_{j}\right) \hat{\varepsilon}\left(\lambda_{j}\right)^{\prime}\left(\sum_{j}^{*} \hat{\varepsilon}\left(\lambda_{j}\right) \hat{\varepsilon}\left(\lambda_{j}\right)^{\prime}\right)^{-1} \sum_{j}^{*} \hat{\varepsilon}\left(\lambda_{j}\right) \psi\left(\lambda_{j}\right)^{\prime}\right) ; \\
\psi\left(\lambda_{j}\right)^{\prime}=\left[\psi_{1}\left(\lambda_{j}\right), \psi_{2}\left(\lambda_{j}\right)\right] ; \quad \hat{\varepsilon}\left(\lambda_{j}\right)=\frac{\partial}{\partial \tau} \log g_{u}\left(\lambda_{j} ; \hat{\tau}\right) ; \quad \psi_{1}\left(\lambda_{j}\right)=\log \left|2 \sin \frac{\lambda_{j}}{2}\right| ; \\
\psi_{2}\left(\lambda_{j}\right)=\log \left|2\left(\cos \lambda_{j}-\cos w_{r}\right)\right|
\end{gathered}
$$

where $\lambda_{j}=2 \pi j / T$, and the summation in * in the above equations is over all frequencies which are bounded in the spectrum. $I\left(\lambda_{j}\right)$ is the periodogram of $\hat{u}_{t}$ defined as

$\hat{u}_{t}=(1-L)^{d_{1 o}}\left(1-2 \cos w_{r} L+L^{2}\right)^{d_{2 o}} y_{t}-(1-L)^{d_{1 o}}\left(1-2 \cos w_{r} L+L^{2}\right)^{d_{2 o}} f(\hat{\phi}, t)$,

where the last term of the above equation, for some special nonlinear cases such as those presented in the following section, can be expressed in a linear way as $\hat{\phi} \bar{f}(t))$, with

$$
\hat{\phi}=\left(\sum_{t=1}^{T} \bar{f}(t) \bar{f}(t)^{\prime}\right)^{-1} \sum_{t=1}^{T} \bar{f}(t)(1-L)^{d_{1 o}}\left(1-2 \cos w_{r} L+L^{2}\right)^{d_{2 o}} y_{t},
$$

where $\bar{f}(t)$ is a linear function of time. Also, $\hat{\tau}=\arg \min _{\tau \in T^{*}} \sigma^{2}(\tau)$, with $T^{*}$ as a suitable subset of the $R^{q}$ Euclidean space. Finally, $g_{u}$ is a known function coming from the spectral density of $u_{t}$ :

$$
\operatorname{sdf}_{u}(\lambda)=\frac{\sigma^{2}}{2 \pi} g_{u}(\lambda ; \tau), \quad-\pi<\lambda \leq \pi
$$

Note that these tests are parametric and, therefore, they require specific modeling assumptions about the short-memory specification of $u_{t}$. In particular, if $u_{t}$ is a white noise, $g_{u} \equiv 1$, while if it is an AR process of the form $\phi(L) u_{t}=\varepsilon_{t}, g_{u}=\left|\phi\left(\mathrm{e}^{\mathrm{i} \lambda}\right)\right|^{-2}$, with $\sigma^{2}=V\left(\varepsilon_{t}\right)$, with the AR coefficients being a function of $\tau$.

The point estimates were obtained by choosing over a grid the values of $d_{1}, d_{2}$, and $r$ that minimize Robinson's (1994) test statistic. They were found to be almost the same as those obtained by maximizing the Whittle function in the frequency domain (Dahlhaus, 1989) in the linear case. 
The confidence intervals were calculated by choosing the values of the differencing parameters for which the null hypothesis could not be rejected at the $5 \%$ level.

Under very general regularity conditions, Robinson (1994) showed that for this particular version of his tests, the limit distribution is given by (10):

$$
\hat{R} \rightarrow_{d} \chi_{2}^{2}, \quad \text { as } T \rightarrow \infty,
$$

where " $\rightarrow d$ " stands for convergence in distribution. Therefore, unlike in the case of other procedures, this is a classical large-sample testing situation. If this test is carried out in the context of(6), the null $H_{o}$ will be rejected against the alternative $H_{a}: d \neq d_{o}$ if $\hat{R}>\chi_{2, \alpha}^{2}$ with $\operatorname{Prob}\left(\chi_{2}^{2}>\chi_{2, \alpha}^{2}\right)=\alpha$. As mentioned before, despite the potentially nonlinear structure of the first equation in (6), its interaction with the second equation will make it linear for some specific nonlinear structures, such as the Chebyshev polynomials in time presented in the following section. ${ }^{3}$

\section{4 | EMPIRICAL ANALYSIS}

We examine the following four series:

1. US annual real GDP,

2. US annual real GDP per capita,

3. US quarterly real GDP,

4. US quarterly real GDP per capita,

for the time period from 1929 to 2015 in the case of annual data, and from 1947Q1 till 2015Q3 in the case of the quarterly data.

We start by considering a linear model with a time trend allowing for unit roots and fractional degrees of integration, specifically, the model given model bu (11) below:

$$
y_{t}=\alpha+\beta t+x_{t}, \quad(1-L)^{d} x_{t}=u_{t}, \quad t=1,2, \ldots,
$$

where the errors are assumed to follow in turn a white noise and an autocorrelated process. However, instead of imposing a parametric ARMA structure on $u_{t}$, we employ a nonparametric method due to Bloomfield (1973) such that the error term is specified exclusively in terms of its spectral density function, which is given by equation (12)

$$
\operatorname{sdf}_{u}(\lambda ; \tau)=\frac{\sigma^{2}}{2 \pi} \exp \left(2 \sum_{r=1}^{m} \tau_{r} \cos (\lambda r)\right)
$$

where $\sigma^{2}$ is the variance of the error term and $m$ is a fixed parameter. This model approximates highly parameterized ARMA models with very few parameters, and producing autocorrelations decaying exponentially as in the AR case. Moreover, it is stationary for all ranges of parameters, unlike in the AR case. ${ }^{4}$

\footnotetext{
${ }^{3}$ See Cuestas and Gil-Alana (2016) for the specification of the Chebyshev polynomials in time in the context of I(d) models.

${ }^{4}$ See Gil-Alana (2004) for its application in the context of fractional integration.
} 
TA B L E 1 Estimated values of $d$ with white noise errors

\begin{tabular}{llll} 
Series & No terms & An intercept & A linear trend \\
\hline $\begin{array}{l}\text { Annual real GDP } \\
\text { Annual real GDP per } \\
\quad 1.22(1.11,1.42)\end{array}$ & $1.45(1.34,1.65)$ & $1.31(1.18,1.58)$ & $\mathbf{1 . 3 6}(\mathbf{1 . 2 3 , 1 . 5 8 )}$ \\
\hline $\begin{array}{l}\text { Quap } \\
\text { Quarterly real GDP }\end{array}$ & $1.09(1.02,1.18)$ & $\mathbf{1 . 4 5}(\mathbf{1 . 3 5}, \mathbf{1 . 6 8})$ & $1.49(1.39,1.68)$ \\
$\quad$ cap & $1.33(1.26,1.42)$ & $1.30(1.22,1.41)$ & $\mathbf{1 . 3 1}(\mathbf{1 . 2 4 , \mathbf { 1 . 4 2 } )}$ \\
\hline
\end{tabular}

In bold, the selected models according to the deterministic terms.

TA B L E 2 Estimated values of $d$ with autocorrelated (Bloomfield) errors

\begin{tabular}{|llll} 
Series & No terms & An intercept & A linear trend \\
\hline Annual real GDP & $1.08(0.98,1.25)$ & $1.10(1.00,1.26)$ & $\mathbf{1 . 1 4}(\mathbf{1 . 0 0 , 1 . 3 2 )}$ \\
\hline $\begin{array}{l}\text { Annual real GDP per } \\
\quad \text { cap }\end{array}$ & $1.29(1.19,1.43)$ & $1.28(1.18,1.42)$ & $\mathbf{1 . 3 3}(\mathbf{1 . 2 2 , 1 . 4 7 )}$ \\
\hline $\begin{array}{l}\text { Quarterly real GDP } \\
\text { Quarterly real GDP per } \\
\text { cap }\end{array}$ & $1.05(0.97,1.19)$ & $1.22(1.11,1.43)$ & $\mathbf{1 . 2 6 ( 1 . 1 4 , \mathbf { 1 . 4 4 } )}$ \\
\hline
\end{tabular}

In bold, the selected models according to the deterministic terms.

Tables 1 and 2 display the estimates of $d$, along with their corresponding 95\% confidence bands, for the three cases of (i) no deterministic terms, (ii) a constant, and (iii) a constant and a linear time trend, assuming in turn that $u_{t}$ is a white noise (Table 1) and autocorrelated as in the model of Bloomfield (Table 2).

In the white-noise case, the time trend is significant in all cases except annual GDP per capita, and the estimates of $d$ are significantly above 1, ranging from 1.31 (quarterly GDP) to 1.45 (annual GDP per capita). When allowing for (weak) autocorrelation as specified by Bloomfield (1973), the time trend is significant in all four cases, and the estimated values of $d$ are still significantly above 1 but smaller.

Given the significance of the time trend in most cases, next we investigate whether it might be nonlinear by using an approach based on Chebyshev polynomials in time that has been shown to perform well in the context of the tests of Robinson (1994) for fractional integration (Cuestas \& Gil-Alana, 2016). Thus, we replace the first (linear) equation in (11) with equation (13)

$$
y_{t}=\sum_{i=0}^{m} \theta_{i} P_{i T}(t)+x_{t}, \quad t=1,2, \ldots,
$$

with $m$ now indicating the order of the Chebyshev polynomial $P_{i, T}(t)$ defined as in (14)

$$
\begin{gathered}
P_{0, T}(t)=1, \\
P_{i, T}(t)=\sqrt{2} \cos (i \pi(t-0.5) / T), \quad t=1,2, \ldots, T ; \quad i=1,2, \ldots
\end{gathered}
$$


TA B L E 3 Estimated values of $d$ with white-noise errors and nonlinear trends

\begin{tabular}{llllll} 
Series & $\boldsymbol{d}$ & $\theta_{0}$ & $\theta_{1}$ & $\theta_{2}$ & $\theta_{3}$ \\
\hline Annual real GDP & $1.31(1.12,1.52)$ & $6727.29(2.92)$ & $-3727.39(-2.51)$ & $665.09(1.25)$ & $-328.19(-1.05)$ \\
$\begin{array}{c}\text { Annual real GDP per } \\
\text { cap }\end{array}$ & $1.37(1.23,1.49)$ & $13,192.94(1.47)$ & $-11,626.58(-1.99)$ & $3762.34(1.91)$ & $-271.74(-0.24)$ \\
Quarterly real GDP & $1.25(1.01,1.57)$ & $6202.24(3.19)$ & $-4108.28(-3.33)$ & $1013.71(2.19)$ & $-524.42(-1.89)$ \\
$\begin{array}{c}\text { Quarterly real GDP } \\
\text { per cap }\end{array}$ & $1.39(1.20,1.68)$ & $10,072.98(2.20)$ & $-10,468.05(-1.93)$ & $5500.76(3.00)$ & $-1523.63(-1.44)$ \\
\hline
\end{tabular}

TA B L E 4 Estimated coefficients with white-noise errors

\begin{tabular}{|c|c|c|c|c|c|c|}
\hline \multirow[b]{2}{*}{ Series } & \multicolumn{3}{|c|}{ Original data } & \multicolumn{3}{|c|}{ Demeaned data } \\
\hline & $\boldsymbol{r}$ & $d_{1}$ & $d_{2}$ & $\boldsymbol{r}$ & $d_{1}$ & $d_{2}$ \\
\hline Annual real GDP & 10 & $0.55^{*}$ & $0.20^{*}$ & 12 & $0.75^{*}$ & 0.01 \\
\hline $\begin{array}{l}\text { Annual real GDP per } \\
\text { cap }\end{array}$ & 10 & $0.64^{*}$ & $0.15^{*}$ & 12 & $0.63^{*}$ & $0.36^{*}$ \\
\hline Quarterly real GDP & 7 & $0.69^{*}$ & -0.01 & 7 & $0.73^{*}$ & $0.14^{*}$ \\
\hline $\begin{array}{l}\text { Quarterly real GDP per } \\
\text { cap }\end{array}$ & 13 & $0.66^{*}$ & 0.04 & 8 & $1.24^{*}$ & -0.13 \\
\hline
\end{tabular}

*Statistical significance at the $5 \%$ level.

(see Hamming, 1973, and Smyth, 1998, for a detailed description of these polynomials). Bierens (1997) and Tomasevic and Stanivuk (2009) argue that it is possible to approximate highly nonlinear trends with polynomials of a rather low degree. This model includes the previous one noting that if $m=0$, it contains an intercept, if $m=1$ it includes a linear trend, and if $m>1$ it becomes nonlinear-the higher $m$ is, the less linear the approximated deterministic component becomes. Combining (13) with the second equation in (11) yields a linear model that can be estimated using least squares (see Cuestas \& Gil-Alana, 2016).

Table 3 displays the estimated coefficients of the Chebyshev polynomials in time along with the estimates of $d$ for the case of uncorrelated errors (almost identical results were obtained with autocorrelated (Bloomfield) disturbances). To allow for some degree of nonlinearity, we set $m$ equal to 3 ; therefore $\theta_{2}$ and $\theta_{3}$ are the coefficients corresponding to the nonlinear trends. Nonlinear behavior is found only in the case of the quarterly real GDP series with the two nonlinear coefficients $\left(\theta_{2}\right.$ and $\left.\theta_{3}\right)$ being statistically significant at the $5 \%$ level; $\theta_{2}$ is also found to be significant in the case of the two real GDP per capita series (annual and quarterly) but not for annual real GDP. Further, the estimated values of $d$ are all significantly higher than 1, ranging from 1.25 (quarterly real GDP) to 1.37 (annual real GDP per capita). ${ }^{5}$

Next, we examine the possibility of a cyclical pattern in the data, and for this purpose we consider a model specified as in (6): the coefficients of the first equation on the deterministic terms were not found to be statistically significant in any case, both with a linear time trend and when allowing for nonlinearities by using Chebyshev polynomials in time. Therefore, we estimate models for both the original and the demeaned series but without time trends, assuming in turn that $u_{t}$ in (6) is a white-noise process, an $\mathrm{AR}(1)$ process, and finally follows the exponential spectral specification of Bloomfield (1973). The results are presented in Tables 4, 5, and 6, respectively.

\footnotetext{
${ }^{5}$ Other nonlinear deterministic transformations (such as Fourier methods) produce insignificant coefficients in all cases.
} 
TABLE 5 Estimated coefficients with AR(1) errors

\begin{tabular}{|c|c|c|c|c|c|c|}
\hline \multirow[b]{2}{*}{ Series } & \multicolumn{3}{|c|}{ Original data } & \multicolumn{3}{|c|}{ Demeaned data } \\
\hline & $\bar{r}$ & $d_{1}$ & $d_{2}$ & $\bar{r}$ & $d_{1}$ & $d_{2}$ \\
\hline Annual real GDP & 10 & 0.01 & $0.32 *$ & 10 & $0.26^{*}$ & $0.12^{*}$ \\
\hline $\begin{array}{l}\text { Annual real GDP per } \\
\text { cap }\end{array}$ & 10 & 0.01 & $0.37^{*}$ & 10 & $0.29^{*}$ & $0.14^{*}$ \\
\hline Quarterly real GDP & 7 & $0.65^{*}$ & $0.40^{*}$ & 7 & $0.25^{*}$ & $0.11^{*}$ \\
\hline $\begin{array}{l}\text { Quarterly real GDP per } \\
\text { cap }\end{array}$ & 13 & 0.00 & $0.29 *$ & 13 & $0.58 *$ & $0.46^{*}$ \\
\hline
\end{tabular}

*Statistical significance at the $5 \%$ level.

TA B L E 6 Estimated coefficients with Bloomfield-type errors

\begin{tabular}{|c|c|c|c|c|c|c|}
\hline \multirow[b]{2}{*}{ Series } & \multicolumn{3}{|c|}{ Original data } & \multicolumn{3}{|c|}{ Demeaned data } \\
\hline & $\bar{r}$ & $d_{1}$ & $d_{2}$ & $\bar{r}$ & $d_{1}$ & $d_{2}$ \\
\hline Annual real GDP & 10 & $0.55^{*}$ & $0.20^{*}$ & 10 & $0.60^{*}$ & $0.32^{*}$ \\
\hline $\begin{array}{l}\text { Annual real GDP per } \\
\text { cap }\end{array}$ & 10 & $0.63^{*}$ & $0.17^{*}$ & 10 & $0.63^{*}$ & $0.26^{*}$ \\
\hline Quarterly real GDP & 7 & $0.69^{*}$ & -0.01 & 7 & $0.73^{*}$ & $0.14^{*}$ \\
\hline $\begin{array}{l}\text { Quarterly real GDP per } \\
\text { cap }\end{array}$ & 13 & $0.66^{*}$ & 0.04 & 13 & $0.91^{*}$ & -0.03 \\
\hline
\end{tabular}

*Statistical significance at the $5 \%$ level.

In the case of white-noise errors (Table 4), the estimated value of $d$ for the original series is 10 years at the annual frequency, and 7 and 13 quarters, respectively, for real GDP and real GDP per capita at the quarterly frequency. The estimated value of $r$ for the demeaned series is 12 at the annual frequency, and 7 and 8, respectively, for real GDP and real GDP per capita at the quarterly frequency. It is also noteworthy that $d_{1}$ is systematically higher than $d_{2}$, which indicates that the long-run frequency is relatively more important than the cyclical one. Specifically, $d_{1}$ ranges between 0.55 (annual real GDP, original data) and 1.24 (quarterly real GDP per capita, demeaned data), while $d_{2}$ oscillates around 0 , being significantly positive for the original series at the annual frequency as well as for both annual and quarterly real GDP per capita in the case of the demeaned series.

Table 5 displays the results under the assumption of AR(1) errors. In this case, the estimated value of $r$ is 10 for the four annual series, while it is 7 and 10, respectively, for quarterly real GDP and real GDP per capita. Moreover, the estimated value of $d_{1}$ is much lower than in the previous case, and is not statistically different from zero for some of the original series. This might be a consequence of the competition with the AR(1) parameter in describing the degree of persistence in the long-run structure of the data. For the demeaned series, the values of $d_{1}$ are significant but smaller than those reported in Table 4 . Besides, $d_{2}$ is now statistically significant in all cases, which implies the presence of a cyclical pattern.

Finally, Table 6 displays the results under the assumption that the error term follows the nonparametric specification of Bloomfield (1973). We consider these the most reliable because this model allows for some degree of weak autocorrelation without affecting the estimation of the 
remaining parameters. ${ }^{6}$ The estimated value of $r$ is now 10 for the two annual series, regardless of whether raw or demeaned data are used. The two differencing parameters are significantly different from zero in one of the four cases examined, with the value of the long-run parameter $d_{1}$ being around 0.60 and that of $d_{2}$ about 0.2 for the original data and slightly higher (about 0.3 ) for the demeaned series; for quarterly real GDP, $r=7, d_{1}$ is around 0.7 and $d_{2}$ is close to zero for the original data but equal to 0.14 (and statistically significant) for the demeaned data; for quarterly real GDP per capita, $r=13, d_{1}$ is equal to 0.66 for the original data and 0.91 for the demeaned data, and $d_{2}$ is statistically insignificant in both cases.

To summarize the main findings, first, there is evidence that when modeling GDP one should allow for long memory and fractional integration, instead of restricting the differencing parameters to be either zero or one; second, both the zero (or long-run) frequency and the other nonzero (cyclical) frequencies play a role, at least in some cases. Awareness of the latter point is important for the purpose of evaluating the effects of shocks, which can affect not only the long-run but also the cyclical structure. However, our modeling approach has the limitation of not being able to discriminate between the effects on the two components, because the error term is of a multiplicative nature and is based on both. Future work will aim to address this issue.

\section{5 | CONCLUSIONS}

This paper proposes a new statistical model for macro series that captures both their long-run behavior and their cyclical properties by including two poles in their spectrum, in addition to both linear and nonlinear deterministic trends. The adopted framework is very general because it also allows for fractional degrees of integration at both long- and short-run memory components, and is suitable for modeling any macro series of interest. As an illustration, in this study it is applied to analyze four US real GDP series (annual and quarterly, per capita as well), and it is found to capture very well the stochastic properties of this series. In particular, both stochastic trends and stochastic cycles are found to be significant, both being mean reverting, but the former being nonstationary and the latter stationary with cycles repeating themselves every 6-10 years. Further, there is evidence of a higher degree of persistence at the long-run frequency. It would also be desirable to report the results of the estimated models visually, but this is not possible owing to the nonparametric nature of the Bloomfield's (1973) approach for the error term used here; it could be done in the case of a parametric ARMA approach but at the cost of having to specify the orders of the short-run components.

Our findings provide useful information to policymakers because they suggest that the effects of shocks to GDP, though long-lived, eventually die away and also that there is an important cyclical component. However, specific policy implications can only be obtained by estimating multivariate models to analyze the nature of the shocks driving GDP fluctuations. Therefore, future work will extend our modeling framework with the aim of distinguishing between different types of shocks affecting trends and cycles separately while still allowing for a flexible degree of persistence.

\section{ACKNOWLEDGMENTS}

L. A. Gil-Alana gratefully acknowledges financial support from MINEIC-AEI-FEDER ECO201785503-R project from 'Ministerio de Economía, Industria y Competitividad' (MINEIC), 'Agencia

\footnotetext{
${ }^{6}$ This is due to the fact that the coefficients in the model of Bloomfield (1973) are stationary for all its values, unlike what happens in the autoregressive models.
} 
Estatal de Investigación' (AEI) Spain, and 'Fondo Europeo de Desarrollo Regional' (FEDER). Comments from the Editor and an anonymous referee are gratefully acknowledged.

\section{O R C I D}

\section{Guglielmo Maria Caporale (D) https://orcid.org/0000-0002-0144-4135 \\ Luis Alberiko Gil-Alana (D) https://orcid.org/0000-0002-5760-3123}

\section{REFERENCES}

Ahtola, J., \& Tiao, G. C. (1987a). Distributions of least squares estimators of autoregressive parameters for a process with complex roots on the unit circle. Journal of Time Series Analysis, 8, 1-14.

Ahtola, J., \& Tiao, G. C. (1987b). A note on asymptotic inference in autoregressive models with roots on the unit circle. Journal of Time Series Analysis, 8(1), 15-18.

Bierens, H. J. (1997). Testing the unit root with drift hypothesis against nonlinear trend stationary with an application to the US price level and interest rate. Journal of Econometrics, 81, 29-64.

Bierens, H. (2001). Complex unit roots and business cycles: Are they real? Econometric Theory, 17, 962-983.

Bloomfield, P. (1973). An exponential model in the spectrum of a scalar time series." Biometrika, 60, 217-226.

Caporale, G. M., \& Skare, M. (2014). Long memory in UK real GDP: 1851-2013: An ARFIMA-FIGARCH analysis. WP 14-14, Department of Economics and Finance. Brunel University London.

Christiano, L. J., \& Fitzgerald, T. J. (1999). The band pass filter. NBER WP 7257.

Chung, C. F. (1996). Estimating a generalized long memory process. Journal of Econometrics, 73(1), 237-259.

Cuestas, J. C., \& Gil-Alana, L. A. (2016). A non-linear approach with long range dependence based on Chebyshev polynomials. Studies in Nonlinear Dynamics and Econometrics, 23, 445-468.

Dahlhaus, R. (1989). Efficient parameter estimation for self-similar process. Annals of Statistics, 17, 1749-1766.

Dalkir, M. (2010). Spurious correlation under fractional integration in output series. Economics Letters, 107(2), 165168.

Dickey, D., \& Fuller, W. A. (1979). Distributions of the estimators for autoregressive time series with a unit root. Journal of the American Statistical Association, 74, 427-431.

Dissanayake, G., Peiris, S., \& Proietti, T. (2020). Fractionally differenced Gegenbauer processes with long memory: A review. Statistical Science, 33(3), 413-426.

Elliot, G., Rothenberg, T. J., \& Stock, J. H. (1996). Efficient tests for an autoregressive unit root. Econometrica, 64, 813-836.

Ergemen, Y. E. (2019). System estimation of panel data models under long-range dependence. Journal of Business and Economic Statistics, 37(1), 13-26.

Fuller, W. A. (1976). Introduction to statistical time series. Wiley.

Gil-Alana, L. A. (2004). The use of the Bloomfield (1973) model as an approximation to ARMA processes in the context of fractional integration. Mathematical and Computer Modelling, 39, 429-436.

Gray, H. L., Yhang, N., \& Woodward, W. A. (1989). On generalized fractional processes. Journal of Time Series Analysis, 10, 233-257.

Gray, H. L., Yhang, N., \& Woodward, W. A. (1994). On generalized fractional processes. A correction. Journal of Time Series Analysis, 15, 561-562.

Hamming, R. W. (1973). Numerical methods for scientists and engineers. Dover

Kwiatkowski, D., Phillips, P. C. D., Schmidt P., \& Shin, Y. (1992). Testing the null hypothesis of stationarity against the alternative of a unit root: How sure are we that economic time series have a unit root? Journal of Econometrics, $54,159-178$.

Mayoral, L. (2006). Further evidence on the uncertain (fractional?) unit root in real GNP. Oxford Bulletin of Economics and Statistics, 68, 901-920.

Michelacci, C., \& Zaffaroni, P. (2000). (Fractional) beta convergence. Journal of Monetary Economics, 45(1), 129-153.

Nelson, C. R., \& Plosser, C. I. (1982). Trends and random walks in macroeconomic time series: Some evidence and implications. Journal of Monetary Economics, 10(2), 139-162.

Ng, S., \& Perron, P. (2001). Lag length selection and the construction of unit root tests with good size and power. Econometrica, 69, 1519-1554. 
Phillip, A., Chan, J., \& Peiris, S. (2018). On generalized bivariate student-t Gegenbauer long memory stochastic volatility models with leverage: Bayesian forecasting of cryptocurrencies with a focus on Bitcoin. Econometrics and Statistics, forthcoming.

Phillips, P. C. B., \& Perron, P. (1988). Testing for a unit root in time series regression. Biometrika, 75(2), 335-346.

Robinson, P. M. (1994). Efficient tests of nonstationary hypotheses. Journal of the American Statistical Association, 89(428), 1420-1437.

Simpson, P. W., Osborn, D. R., \& Sensier, M. (2001). Modelling business cycle movements in the UK economy. Economica, 68(270), 243-267.

Smyth, G. K. (1998). Polynomial approximation. John Wiley \& Sons, Ltd.

Stengos, T., Yazgan, M. E., \& Ozkan, H. (2018). Persistence in convergence and club formation. Bulletin of Economic Research, 70(2), 119-138.

Tomasevic, N. M., \& Stanivuk, T. (2009). Regression analysis and approximation by means of Chebyshev polynomial. Informatologia, 42(2), 166-172.

Wu, H., \& Peiris, S. (2018). An introduction to vector Gegenbauer processes with long memory. Statistics, 7, 1.

How to cite this article: Caporale GM, Gil-Alana LA. Trends and cycles in macro series: The case of us real GDP. Bull Econ Res. 2021;1-12. https://doi.org/10.1111/boer.12278 